\title{
Wolfgang Lubitz: On the Occasion of His 60th Birthday
}

\author{
Klaus Möbius $\cdot$ Kev M. Salikhov
}

Published online: 13 November 2009

(C) Springer 2009

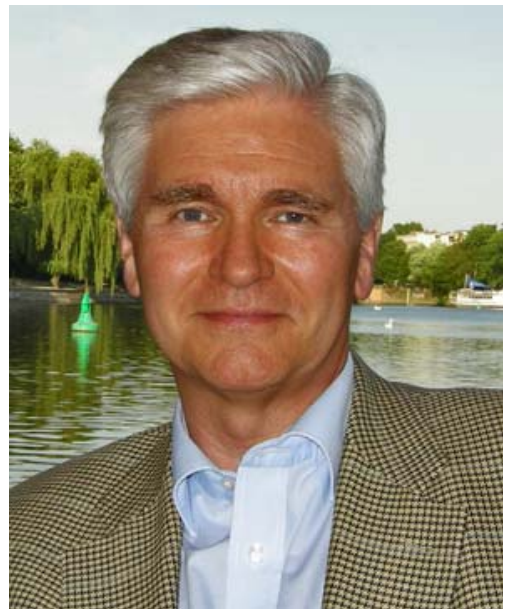

This volume of Applied Magnetic Resonance (AMR) is dedicated to Wolfgang Lubitz (Max Planck Institute for Bioinorganic Chemistry, Mülheim/Ruhr) who celebrated his 60th birthday on 23 July 2009. With such a special issue, a Festschrift as it was called previously, a good academic tradition is continued to honor scientists who had a major impact in their field. Who else if not Wolfgang should

K. Möbius

Department of Physics, Free University Berlin, Berlin, Germany

K. M. Salikhov $(\bowtie)$

Zavoisky Physical-Technical Institute, Russian Academy of Sciences, Kazan, Russian Federation e-mail: salikhov@kfti.knc.ru 
fulfill this criterion, and we are delighted that so many of Wolfgang's colleagues and friends, who had been invited to contribute to the special issue, did not hesitate to accept. Thereby they set a signal that they esteem what has been achieved by Wolfgang and his coworkers in the field of multi-resonance and multi-frequency EPR spectroscopy on biochemical and biological systems.

The 62 papers collected in this Festschrift are meant to be a compliment from the EPR community to provide typical examples of applications and methodological developments in a field where Wolfgang has left so many distinctive footsteps. We hope that the balanced mixture of papers either reviewing selected topics or presenting detailed treatments of novel subjects will be appreciated by Wolfgang and, additionally, will be of interest for a wide audience of senior and junior scientists. The Festschrift is opened by the rather unorthodox contributions from two grand men in the field, George Feher (University of California, San Diego) and Giovanni Giacometti (University of Padua), contemplating on "aging" (a fate we all face, even youngsters like Wolfgang) and on "which came first: photosynthesis or respiration" (a question more fundamental than the "hen or egg" dilemma). After this first course of the birthday menu, it continues with the main course comprising contributions from photosynthesis, metallo-proteins, spin labels, new materials and spin chemistry. Finally, the somewhat heavy dessert course highlights contributions from instrumentation developments and modern theory applications. By this assortment of examples, a glimpse of areas should be caught in which Wolfgang has excelled during recent years and continues to do so.

Wolfgang Lubitz was born in Berlin in 1949 shortly after the end of the Berlin Blockade (during 24 June 1948 to 11 May 1949 the Soviet Union had blocked all transit routes for railway, road and waterway access to West Berlin with its three sectors under the control of the Western allies. The West Berliners had to be kept alive by the Air Lift of the US, UK and French air forces). After coining years of "learning by doing", both at school and outside, Wolfgang studied chemistry at the Free University (FU) Berlin, which had been founded just the year before he was born (as a split-off from the East Berlin university, the later Humboldt University, where freedom of expression and democratic learning were no longer possible in that dark period of the Cold War). At the FU Berlin, Wolfgang received both his diploma degree (in 1974) and doctoral degree (in 1977) under the joint supervision of Profs. Harry Kurreck (Department of Chemistry) and Klaus Möbius (Department of Physics). Their open-minded approach to interdisciplinary and international collaboration with many groups from chemistry, physics and biology, as well as their enthusiasm for borderline research was wholeheartedly shared by Wolfgang and resulted in mutual confidence and enduring friendship among them. From 1977 to 1982 Wolfgang worked for his habilitation in organic chemistry at the FU and, indeed, international and interdisciplinary research in EPR and ENDOR/TRIPLE became sort of trademark for his scientific and personal life. From 1979 to 1989 the FU Berlin had hired Wolfgang Lubitz, first as an Assistant Professor, later as an Associate Professor at the Chemistry Department.

From 1983 to 1984 Wolfgang worked as a Max Kade Fellow at UC San Diego in the Physics Department with Prof. George Feher on EPR and ENDOR in photosynthesis. There he received an in-depth training of handling photosynthetic 
reaction center proteins and their purification techniques. With George Feher, a relation of mutual respect and trustfulness developed and, indeed, this year was a very happy time for Wolfgang, his wife Gisela and son Felix. The fruitful and enjoyable collaboration with George Feher and his group continued over the years and lasts until now, as his frequent research visits to them so convincingly demonstrate.

In 1989 Wolfgang accepted an offer of the University of Stuttgart as an Associate Professor of Experimental Physics. But already in 1991 he returned to Berlin, this time to the Technical University (TU), as a Full Professor of Physical Chemistry at the Max Volmer Institute. In the following years he turned the Max Volmer Institute into a "Mecca" for EPR spectroscopy on photosynthetic and other proteins, always in close cooperation with other EPR groups in Berlin. They were strongly supported by the Deutsche Forschungsgemeinschaft (DFG), for instance by means of sustaining research programs such as the Sonderforschungsbereiche (Collaborative Research Centers) SFBs 337 and 498 ("Energy- and Charge-Transfer in Molecular Aggregates" and "Protein-Cofactor Interactions in Biological Processes") as well as the Schwerpunktprogramm (Priority Program) SPP 1051 ("High-Field EPR in Biology, Chemistry and Physics").

At the TU Berlin, Wolfgang stayed until 2000 when he became a Scientific Member of the Max Planck Society and Director at the Max Planck Institute for Radiation Chemistry (later renamed Max Planck Institute for Bioinorganic Chemistry) in Mülheim/Ruhr. In the same year, Wolfgang became an Honorary Professor of the Heinrich-Heine-University of Düsseldorf. Currently, he is Managing Director of the Max Planck Institute in Mülheim. And again, Wolfgang turned his laboratory into an outstanding EPR center for protein research, uniquely equipped with advanced EPR spectrometers for multi-frequency research. They range from very low to very high microwave frequencies and magnetic fields, ready for continuous wave or pulse operation. The EPR experiments are supplemented by quantum chemical calculations and other spectroscopic techniques. Moreover, Wolfgang's biochemical and protein handling infrastructure, which he had built up over the years, guarantees biological samples of highest purity standards; certainly a prerequisite for success in protein spectroscopy.

Wolfgang Lubitz has (co)authored more than 300 publications in scientific journals and books. His more than 20 review articles are a delight to read both for experts and newcomers. He and his coworkers have significantly contributed to the understanding of light-induced charge separation in bacterial and plant photosynthesis, the most important electron-transfer process on Earth. This success was possible by studying the cofactor radicals, radical pairs and triplet states embedded in their protein matrix and created as transient intermediates in this process. In more recent years his research focus has shifted to the enzymes that play a crucial role in hydrogen metabolism, the hydrogenases. To understand their function on the molecular level is of key importance for future strategies of renewable energy supply. Examples of his current research are the investigations of catalytic metal centers in metallo-proteins, such as the $[\mathrm{NiFe}]$ and $[\mathrm{FeFe}]$ hydrogenases, as well as the $\mathrm{Mn}_{4} \mathrm{Ca}$ cluster in the water splitting complex of plant photosynthesis. 
Wolfgang has a specific talent for lecturing about his scientific work. He is able to fascinate his audience for his subject in particular and for science in general. And it is always a pleasure to follow his clear arguments and to indulge in his beautiful illustrations. This explains the vast number of his invited lectures he gave at international conferences and workshops throughout the world (fortunately, he enjoys traveling and a world-wide reputation as a gourmet). Such lectures are highlights in our difficult commitment to bridge the gap between the scientific and public communities. In fact, they are appreciated as an important means for disseminating scientific results to a wider audience. Possibly, such lectures are more relevant in the public dialogue on science and technology than papers in scientific journals can ever be, which are normally written for the experts. But despite these concerns, we are optimistic that the papers collected in this Festschrift will be an exception to the rule.

Wolfgang Lubitz is member of a dozen scientific organizations, for example, the Gesellschaft Deutscher Chemiker, the Deutsche Gesellschaft für Biophysik, the Biophysical Society (USA), the International Society for Bioinorganic Chemistry, the International Society of Photosynthesis Research and the International Society of Magnetic Resonance. Wolfgang was the President of the International EPR/ESR Society 2005-2008. In addition to many other awards and fellowships, he received the Zavoisky Award (Russia, 2002) and the Bruker Lecturer Prize (UK, 2003). He became Fellow of the Royal Society of Chemistry (UK, 2004). He received the Gold Medal of the International EPR/ESR Society (2005) and an Honorary Doctor of Philosophy from the University of Uppsala (Sweden, 2008). Most recently, he was honored to present the Malcolm Dole Distinguished Summer Lectures in Physical Chemistry at Northwestern University in Evanston (USA, 2009).

The Guest Editors want to thank all the authors of this special issue who reacted so positively to our invitation to contribute. We also thank the referees who did a great job, even under the pressure of closing deadlines, by providing constructive criticism for improving the submitted manuscripts. Finally, we express our gratitude to Dr. Laila Mosina for her support and encouragement to get this special issue published still in the year of Wolfgang Lubitz's 60th birthday. 